\title{
EMPLOYER BRANDING THROUGH SOCIAL MEDIA: THE CASE OF LARGEST POLISH COMPANIES
}

\author{
Kalina Grzesiuk ${ }^{1}$, Monika Wawer ${ }^{2}$ \\ Department of Enterprise Management, Faculty of Social Sciences, \\ John Paul II Catholic University of Lublin, Al. Raclawickie 14, 20-950 Lublin, Poland \\ E-mails: ${ }^{1}$ kalina.grzesiuk@kul.pl; ${ }^{2}$ monika.wawer@kul.pl (corresponding author)
}

\begin{abstract}
The main purpose of this article is to evaluate the current state of network communication channels in an organization and to propose recommendations for their development as a part of external employer's brand-building strategy by an example of selected Polish enterprises. This paper reviews the social network tools used thus far by the 100 Largest Polish Private Companies listed in 2017 Forbes Magazine report. The analysis involves not only their Internet presence and the way these enterprises are presented but also the level of interactivity of their activities in selected social media (e.g. Facebook, YouTube, LinkedIn, Twitter). The results show that most of the companies examined have not adopted a systematic approach to the employer branding practices they use. Therefore, a conclusion might be drawn that, although these enterprises are present in the social media networks, and they use various external communication channels in order to reach their stakeholders, they still fail to adopt a strategic orientation in developing their activities.
\end{abstract}

Keywords: employer branding, employer attractiveness, social networking, social media, human resources.

JEL Classification: L14, M12, M31, M51.

\section{Introduction}

The strategic importance of human resources in an organization has been greatly increased by the contemporary global labour market. Acquiring and retaining highly qualified employees has become a serious challenge for managers in many companies. In order to recruit the best workers available and scout talents, employers undertake various initiatives, which show their competitive advantage (Kucherov \& Zavyalova, 2012).

The view that the employees' loyalty in a given organization, or their involvement in the tasks performed, can be increased by building the company's image as a good and fair employer has become increasingly popular in recent years. Empirical studies show a correlation between positive image of the employer and high employee commitment (Dögl \& Holtbrügge, 2014). The studies also confirm that emotional factors related to pride in being employed by a given employer may affect individual involvement of the staff four times as strongly as the rational factors such as the amount of remuneration and additional benefits (Gibbons, 2006).

Enterprises with a positive image in the labor market are able to recruit the most talented employees, while incurring lower employment costs on many occasions. Such companies have lower staff turnover and absenteeism rates, and at the same time a more committed and satisfied team of employees, which often translates to the company's better financial results and higher competitiveness (Edwards, 2010).

Attracting the best candidates successfully can be achieved by creating the company's image as an attractive employer and combines the right personnel strategy and a strategy for the company's communication with its environment. One of the key challenges in this respect is employer branding through the use of social media.

\section{The essence of employer branding in an organization}

The concept of employer brand (EB) was first defined of by Ambler and Barrow (1996, p. 187). They viewed EB as "the functional, economic and psychological benefits that are provided by employment, and identified with the employing company". Employer branding is currently understood as the sum of a company's efforts to communicate to existing and prospective staff that it is a desirable place to work (Lloyd, 2008). It is also seen as the company's long-term strategy aimed to iden- 
tify, recruit and retain the most talented and valuable employees (Dögl \& Holtbrügge, 2014). Thus, the concept of employer branding encompasses all the efforts of the organization aimed at existing and potential employees, whose purpose is to create an attractive image of the employer and support their strategic business goals (Bellou, Chaniotakis, Kehagias, \& Rigopoulou, 2015).

Among the employer's branding efforts there are activities directed internally and externally in the company. These efforts are divided into two types of employer branding and depend on the employee group they are targeted at (Sengupta, Bamel, \& Singh, 2015):

- internal - covering efforts addressed at existing employees and aimed primarily at creating a friendly working environment, ensuring the possibility of employee development and building organizational engagement,

- external - covering efforts undertaken outside of the company and addressed at potential employees, and seeking to build the employer image to be seen as attractive.

It is of great importance that these two directions of impact are mutually consistent. Employer branding is therefore aimed at creating the best image of the employer in the eyes of both current and potential employees. Thanks to it, it is possible not only to attract talents, but also to retain them and increase their job satisfaction. Miles and Mangold (2004) drew attention to an important aspect of employer branding which assumed that working in a specific company is a special commodity that, just like everyone else, needs to be skillfully sold using external communication.

The image of the company as an employer is understood as the company's image formed in the awareness of its current and future employees on the basis of their personal experience or information that has reached the potential members of the organization, the source of which are both people who create the organization as well as all types of mass media. This definition emphasizes the importance of the opinions and experiences of different people who refer to many sources of data currently coming primarily from the Internet in the process of creating of the organization's image.

The image of the employer is an important message that influences the acquisition of candidates who will later support the entrepreneurship culture and desirable values in their future work. It provides the company with visibility among potential employees and helps the company become the employer of choice among top talent candidates (Chunpinga \& Xib, 2011). The name "employer of choice" is most often given to organizations where current and potential employees perceive the work environment as particularly attractive for the development of their careers.

Research confirms that companies that undertake efforts to establish their image as a positive one are seen by candidates as a first-choice employer brand (Rampl, 2014). This term signifies that a company has a strong and recognized brand and offers a possibility of first-rate employment (Aboul-Ela, 2016). The company becomes a trusted enterprise that employees can be proud of, and whose management team cares about individual needs of its employees facilitating their professional and personal development, ensuring cooperation with the supervisor listening to the expectations of subordinates. Thus, employer branding can be considered as an important factor not only in the implementation of the personnel strategy, but also as a condition for the success of the entire organization and an important indicator of the company's value.

A contemporary candidate is constantly present in social media. The Millennials in particular tend to stay in touch with each other constantly (Alnıaçık, E. \& Alnıçık, Ü., 2012; Reis \& Braga, 2016). They share information primarily through posts, likes, photos or comments on many social websites. For this reason, the company's internet presence as well as the content of messages posted in the Internet is of such great importance in external employer branding.

\section{Social media}

Contemporary companies operate in an extremely demanding environment. Due to the fast development of ICT technology and its accessibility, the stakeholders have numerous opportunities, as never before, to get information and to participate in the companies' lives. That is why firms start to get involved in the Web 2.0, a platform allowing its users not only to publish content, but also to join various projects requiring cooperation with other users. It's a technological platform that has several functionalities such as software supporting animation, interactivity and online streaming (Adobe Flash Player) or a web feed for the frequent publishing of a varied content (Really Simple Syndication).

All these features allow the participants to co-create and modify both the content and the applications (Kaplan \& Haenlein, 2010). An important aspect of a company's presence in the web 
2.0 is User Generated Content. The term relates to the various means that allow their users to communicate and exchange the content online (Smith, Fischer, \& Yongjian, 2012). They can take diverse forms across the several types of social media.

Social media (SM) can be defined as "a group of Internet-based applications that build on the ideological and technological foundations of Web 2.0, and that allow the creation and exchange of User Generated Content" (Kaplan \& Haenlein, 2010). The most prominent among them is Facebook, Twitter, YouTube, and, in a professional context, LinkedIn. The number of social media users grows yearly. At the end of 2017 the number of participants globally reached 2,46 billion and it is projected to grow to 3,02 by 2021 (www.Statista.com).

The key advantage of social media in relation to the traditional channels of the company's communication is that the user becomes both the producer and the consumer of information. It means that every user can create, edit and disseminate information (Tavleen, 2013). The contact through social media is more personal, realistic and interactive, as well as cost efficient and wide ranging, however it is less controllable (Kissel \& Büttgen, 2015). For the companies that means having increasingly less control over the information about them in the cyberspace (Kaplan \& Haenlein, 2010).

Social media can be divided into four main groups of activities (Smith et al., 2012; Tavleen, 2013):

- Social networking sites (SNS) - Facebook, Myspace,

- Content sharing sites - YouTube, Flickr,

- Blogs and microblogs - Twitter,

- Collaborative projects - wikis.

SNS are "web-based services that allow individuals to (1) construct a public or semi-public profile within a bounded system, (2) articulate a list of other users with whom they share a connection, and (3) view and traverse their list of connections and those made by others within the system" (Aguenza \& Som, 2012). All the three features influence the mechanisms governing users' behaviours in the network. Moreover, the opportunity to create and publish a profile allows taking a strategic approach to shaping and publicly show user's identity.

Kietzmann, Hermkens, McCarthy and Silvestre (2011) introduced a model showing seven main elements of social media in a form of honeycomb. They include dentity, conversations, sharing, presence, relationship, reputation and groups.
The area of identity concerns sharing the content with other users, data privacy controls and tools for user self-promotion. The main aspect of this area is whether users are willing to disclose personal information like thoughts, feelings, their likes and dislikes on their social media profiles. In general, the type and amount of the information shared depends on the aim. Different social network sites are used for different purposes. LinkedIn is mostly treated as a tool for the recruitment process both for the employers and job seekers (Chiang \& Suen, 2015). That's why the creation of a public profile is often a strategy taken by users in order to present themselves in a positive way. Such a profile is also used by the employers as a way of selecting the right candidates for the job (Smith \& Kidder, 2010).

Social media's aim in the area of conversations is to facilitate talking to other users. The ways in which people communicate differ in different media. Twitter is sometimes treated as a micro-blog and it is aimed at exchanging small elements of content such as videos and images, and sending short (up to 140 characters) messages (Kaplan \& Haenlein, 2011). That is why they are considered being halfway between SNS and blogs. As compared to Facebook Twitter is focused more on the sharing of opinions rather than building a reciprocal social interaction (Hughes, Moss, Batey, \& Lee, 2012).

Sharing focuses on exchanging, distributing and receiving various elements of content by the users. Publishing them on the SNS is a part of presenting themselves and their identity, but also allows finding other people that are in some ways similar, as they share the same interests (Utz, 2015).

Relationships between users are the focus of an another part of the honeycomb. The main concern here is the way people relate to each other. This, in turn, influences the flow of information and other content between them. The SNS networks operate in similar ways as the networks of actors in society. Peoples decisions and behaviours are depenedant on the relations with others and that is the basic assumption of the social embeddeness theory (Granovetter, 1985).

Social media also play an important role in building the users' reputation. There are many mechanisms that support building trust and a positive image of a company. They are usually based on the positive evaluation by other users. These tools help to build a good reptation on the basis of two features: range (popularity) and emotional relation towards user. In relation to the social media being part of research in this article, 
these characteristics include: for Facebook - a number of followers, observing and likes; for Twitter - a rating based on users opinions and a number of followers; for YouTube - a number of views and likes; for LinkedIn - a number of followers; and for all of the mentioned above $-\mathrm{a}$ number of comments containing the positive and negative emotional load, which is often referred to as the sentiment (Stieglitz \& Dang-Xuan, 2013).

Groups and their functioning in the network setting are the last of the mentioned elements of social media. There are two main types of groups created in the SNS (Rosaci \& Sarne, 2014). The first kind is created by an individual user, who divides her/his colleagues and friends into specific groups. It is a convienient tool for differentiating their access to the information published on the user's profile. That way one can decide which elements of identity will be shown to which group. The second type of groups is generated by the users representing some community of interests. They can vary in a way they can be accessed, since there are open groups where every SNS user can easily become a member. However, there are also some closed groups where the membership is being granted individually by the group moderator.

\section{Employer branding in social media}

Social media enable creating public profiles of the members and make their social connections visible. It is a great opportunity to get connected to other users and their extended network of friends. For an employer that means getting access to a wide range of potential active and passive job seekers. Social media platforms can serve as an appropriate cyberspace to promote and connect themselves with the actual and prospect employees. Therefore many companies use their public profiles on the SNS as a way of advertising job vacancies on the internet and, as many studies show, it influences positively the impression of the organization (Theurer, Tumasjan, Welpe, \& Lievens, 2018).

Social network sites offer both the employers and the job-seekers an increasing convenience and accessibility and these features make them a highly frequent channel for accessing the information necessary during employment searches (Kissel \& Büttgen, 2015). Candidates can experience company in a more manifold, lively and realistic way, which allows the creation of a more holistic picture of a company. It can become an effective tool for attracting talented candidates in a situation when lack of the highly specialised job candidates becomes one of the labour market trends especially in highly developed economies.

The Society for Human Resource Management conducts surveys concerning "Using the social media for talent acquisition" ("SHRM Survey Findings: Using Social Media for Talent Acquisition - recruitment and Screening", 2016). In 2015 this organization asked 399 firms to describe their practices for making use of social media during the recruitment process. The results of the research show that $84 \%$ of the companies used SM in seeking the job candidates. The main reasons for doing that were opportunities for recruiting passive job candidates who might not otherwise apply or be contacted by the organization; increasing employer brand and recognition; and targeting job candidates with a very specific set of skills.

The social media this article concerns were among the most frequently used by the companies: LinkedIn (96\%), Facebook (66\%), Twitter $(53 \%)$, and YouTube $(11 \%)$. LinkedIn was also the site that was indicated as the most effective one by $73 \%$ of them. Firms use social media mostly for posting job advertisements (89\%), contacting candidates or potential candidates $(75 \%)$ and searching for passive and active job candidates by using the social networking website's search feature (accordingly 73 and 67\%). However, the companies also saw some downsides of using social media in the employment process. They had concerns about legal risk of discovering information about protected characteristics like age, race, gender or religious affiliation. Adapting new practices requires spending more time and resources and the employers were reluctant to delegate HR staff to spend more time on the new, additional recruitment method. Moreover, some of the companies' representatives questioned the credibility of the information the candidates published in their profiles.

\section{Implementation of employer branding strategy and social media in Poland}

\subsection{Employer branding in Poland}

In 2017 the HRM Institute conducted its sixth research which served as the basis for a comprehensive report on how employer branding has changed in recent years (HRM Institute, 2017).

The research was conducted using the CAWI surveying technique. The survey was addressed to Polish employers, and in particular to representatives of HR, EB, marketing and communication departments responsible for employer branding 
activities in the companies. A total of 399 organizations from various industries and of various sizes took part in the research.

The results indicate that only $14 \%$ of the surveyed companies have a clearly defined employer branding strategy, and $32 \%$ of the organizations work on the strategy in order to expand it. Unfortunately, $50 \%$ of Polish companies admit that they do not have an EB strategy, $21 \%$ of which do not plan any activities in this area, and $29 \%$ of which notice the need to have such a strategy and are currently working trying to create one. It seems important that the participants of the "Employer branding in Poland 2017" research see the EB's benefits that may be most beneficial for them. These primarily include: the ease of attracting talents to the organization (86\%), consistent communication in the company (86\%), improved matching of candidates to the organizational culture (76\%) and an improved level of employee involvement in the company (75\%). It is also vital for the respondents to have a strategy for lowering the costs of the company's operations, i.e. reducing staff turnover or reducing the costs associated with recruitment.

To sum up, the research results indicate that employers are aware of the fact that the lack of a strategic approach to building the company's external and internal image may lower the company's attractiveness, and thus also its competitiveness. For this reason, they have outlined the main areas of investments in EB in 2018. These areas include the employer's brand internal communication $(14 \%)$, external communication $(13 \%)$ and a strategy for using social media (11\%).

\subsection{Social media in Poland}

The average percentage of the companies in Poland that have their own website in 2017 was $69.9 \%$, however for the large companies (250 and more employees) it was 91.9\% (Anon, 2017). However, the use of social media in Polish firms is still very low. Poland was listed in the last position among the European Union countries by the use of SM in the enterprises in 2016. The percentage of companies using social network tool varies and it is dependent on the company's size, the type of economic activities and the geographic location.

The results of the 2017 Polish Central Statistical Office's survey show that social network sites $(54.6 \%)$ were the most popular types of social media among large Polish enterprises in 2017, with multimedia content sharing websites (35.9) and enterprise's blogs and microblogs (18.7\%) at the second and third place. Firms were not very interested in using the Wiki tools (12.6\%). Moreover, more than a half of the large companies (58.4\%) used at least one of these social media types. It seems that the enterprises in Poland are aware of the benefits of an effective company website as a tool for differentiating themselves from their competition and increasing their overall attractiveness. However the specific features of social media such as constant connectivity, opportunity to have long-time conversations with their stakeholders and the easy of identity sharing (Priyadarshini, Kumar, \& Jha, 2017) are still underappreciated by them.

\section{Methodology}

The research described in this paper was based on a case study method. It involved the review of the social network tools used thus far by the 100 Largest Polish Private Companies listed in 2017 Forbes Magazine report (Forbes, 2017). The authors of the report have assumed that a Polish company is understood as a business entity in which the majority of shares belong to a Polish entrepreneur or a group of such people acting together. The group of such business entities also includes companies in which the entrepreneur has a minority share but actively manages or controls them through the supervisory board. The company's place in the list was determined by the company's market value (Enterprise Value, "EV") calculated according to current financial data available.

In order to conduct an in-depth analysis, all companies included in the list were divided into three groups according to their value. A detailed representation of data is illustrated in Table 1.

Table 1. Research group sample according to EV (source: Forbes, 2017)

\begin{tabular}{|l|c|c|}
\hline Enterprise value range & $\begin{array}{c}\text { Number of } \\
\text { companies }\end{array}$ & $\begin{array}{c}\text { Average } \\
\text { enterprise } \\
\text { value }\end{array}$ \\
\hline up to 1000 million PLN & 40 & 822 \\
\hline $\begin{array}{l}1000 \text { to } 5000 \text { million } \\
\text { PLN }\end{array}$ & 49 & 1743 \\
\hline above 5000 million PLN & 11 & 10241 \\
\hline Total & 100 & 2230 \\
\hline
\end{tabular}

The main purpose of this article is to evaluate the current state and to propose recommendations for the development of the company's network communication channels as a part of the external employer brand building strategy on the example 
of the selected Polish enterprises. The analysis involves not only their presence on the Internet, but also the way these enterprises are presented and the level of interactivity of their activities in the social media most often used both in the world and in Poland, i.e. Facebook, LinkedIn, YouTube, and Twitter. In order to make sure the account was actively used by the company the authors had selected a time period of 30 days from January 15th and February $15^{\text {th }} 2018$ to check whether there was any activity on the social media account of the firm.

\section{Results}

The first stage of research into selected global social media, i.e. Facebook, LinkedIn, YouTube, and Twitter concerned the total number of SNSes on which the most valuable companies in Poland have their official profiles. The results show that only $14 \%$ of companies have accounts on all 4 of the aforementioned websites, while the largest number of enterprises (38\%) is to be found on 3 of the websites (Table 2).

Nearly a third of the enterprises are present on only two of the analyzed sites, whereas $6 \%$ of the total number of the companies are completely absent from SNS. It is interesting to notice that in each group which corresponds the company's estimated EV, the majority of enterprises decided to implement the presence strategy on 3 of the sites simultaneously.

Interesting results have been gathered through a detailed analysis of the presence and activity of companies on the websites selected for research. Almost three quarters of the Polish largest privatelyowned companies $(73 \%)$ have their official Facebook profiles. However, not all of them were active in the time period selected for the research. 63 companies published at least one post and, based on this fact, they were considered active users.

Almost all of the largest Polish private companies $(92 \%)$ were present on the LinkedIn social network site. However, as it was in the case of Facebook, not all of them are active users. Although they have official profiles as employers, they do not actively publish any updates. Only 55 of them had any updates on their profiles. Employers seem to be much less interested in YouTube where 63\% of companies have their official profiles, but only half of them are active users (32\%). The last site included in the research was Twitter, which, despite the fact that it has the least number of companies present on the site (a total of 22), has the highest active vs present ratio (91\%). It can therefore be deduced that the companies that have been running their accounts on the site are particularly active in building relationships with stakeholders.

Table 2. Company SNS presence

\begin{tabular}{|c|c|c|c|c|c|}
\hline & $\begin{array}{l}\text { Number of } \\
\text { companies }\end{array}$ & $\begin{array}{l}\text { up to } \\
1000\end{array}$ & $\begin{array}{c}1000- \\
5000\end{array}$ & $\begin{array}{c}\text { above } \\
5000\end{array}$ & Total \\
\hline \multirow{3}{*}{ 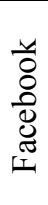 } & Present $(\mathrm{P})$ & 32 & 30 & 11 & 73 \\
\hline & Active (A) & 25 & 28 & 10 & 63 \\
\hline & $\begin{array}{l}\text { Active vs. } \\
\text { present ratio }\end{array}$ & $78.1 \%$ & $93.3 \%$ & $90.9 \%$ & $86.3 \%$ \\
\hline \multirow{3}{*}{ 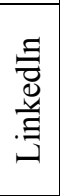 } & Present & 38 & 43 & 11 & 92 \\
\hline & Active & 20 & 27 & 8 & 55 \\
\hline & \begin{tabular}{|l|} 
Active vs. \\
present ratio
\end{tabular} & $52.6 \%$ & $62.8 \%$ & $72.7 \%$ & $59.8 \%$ \\
\hline \multirow{3}{*}{ 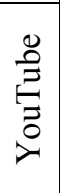 } & Present & 23 & 32 & 8 & 63 \\
\hline & Active & 10 & 15 & 7 & 32 \\
\hline & $\begin{array}{l}\text { Active vs. } \\
\text { present ratio }\end{array}$ & $43.5 \%$ & $46.9 \%$ & $87.5 \%$ & $50.8 \%$ \\
\hline \multirow{3}{*}{ 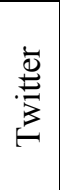 } & Present & 5 & 14 & 3 & 22 \\
\hline & \begin{tabular}{|l} 
Active \\
\end{tabular} & 5 & 12 & 3 & 20 \\
\hline & \begin{tabular}{|l|} 
Active vs. \\
present ratio
\end{tabular} & $100 \%$ & $85.7 \%$ & $100 \%$ & $90.9 \%$ \\
\hline \multirow{5}{*}{ 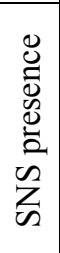 } & 4 SNS & 3 & 9 & 2 & 14 \\
\hline & $3 \mathrm{SNS}$ & 17 & 15 & 6 & 38 \\
\hline & 2 SNS & 12 & 13 & 3 & 28 \\
\hline & $1 \mathrm{SNS}$ & 5 & 9 & 0 & 14 \\
\hline & $0 \mathrm{SNS}$ & 3 & 3 & 0 & 6 \\
\hline
\end{tabular}

Taking the above into consideration, further analysis into the level of interactivity of companies activities can be suggested.

\subsection{Facebook}

The analysis of the companies' presence on Facebook shows that there are some interesting regularities in relation to the company value. The structure of the enterprises present on this SNS seems to be consistent with the general structure of the sample in relation to the company value. However, the structure of the firms without an official profile on FB is significantly different. The lack of interest in this SNS is especially seen within the group of companies having medium value $(70 \%)$.

Analyzing the companies' activity characteristics on Facebook involved identifying the number of posts, reactions (including both positive and negative emotions) and shares among all the active firms. The results presented in Table 3 show that the medium-sized companies were the most active on Facebook by the number of posts per company $(18,57)$ in comparison to the average 
number of posts of all the selected firms $(16,85)$. The number of posts exceeded the average for the largest companies too $(17,6)$, however, the smallest companies $(14,64)$ were characterized by the lowest level of activity.

The number of reactions both per post and per company seem to confirm these results as the medium-sized firms had almost twice as many users' reactions as the groups of the largest and the smallest companies in the sample. The notion is also supported by the results of the analysis of the number of shares.

\subsection{LinkedIn}

The firms that do not have LinkedIn profiles are in $75 \%$ among the medium-sized ones and in $25 \%$ among the smallest ones. There no large company is absent on this professional SNS. The structure of the active firms is also similar to the sample, but the number of inactive companies is a bit higher in the smallest ones.

The companies present on the LinkedIn network have a rather wide range of followers (from 0 to as much as 30367) with 2027 users following a company's profile on the average. The number of followers is dependent on the firm's size, as larger companies have, on the average, more followers (Table 3). The analysis of the number of posts, likes and comments is narrowed to the companies that are active on LinkedIn and publish updates. The same relation, as in the number of followers, is visible in the number of posts per company and comments per post. However the number of posts published and the number of likes in general and in relation to the number of posts, do not give consistent results.

The analysis shows that the main form of the company communication is publishing updates, as the post are not very popular, especially if we compare it to the number of posts per company with Facebook. The same goes for the number of comments. The average below 1 means that, although the number of users is relatively high, they aren't willing to leave their comments.

\subsection{YouTube}

The results presented in Table 3 show that the medium-sized companies were the most active on YouTube in each of the detailed criteria, i.e. number of subscriptions, number of videos (30 days), number of videos per active company, number of views per company, number of positive and negative reactions per company, recommended channels and number of views per company. This corresponds directly to the results found for Facebook. This kind of activity is several times (two, three, and even many times) greater in many areas of comparison found in the research.

It is worth emphasizing the fact that the positive reactions per company ratio is clearly larger than the ratio of negative reactions per company ( 2 times larger for the less valuable companies and 4 times larger for the companies of medium and high value). This means that activities undertaken by companies on the Internet are well perceived and can contribute to the creation of a positive image of the employer on the labour market.

Due to a specific character of the YouTube site, the interactivity of activities of the companies present on the site should be highly appreciated. The fact that a total of 213 films were uploaded to the site and viewed by 185.500 people within the period of 30 days shows a visible relationship between companies and recipients of their employer branding activities.

\subsection{Twitter}

Twitter is the social media site that turned out to be the least popular among the largest privatelyowned companies in Poland (Table 3). Only 22\% of the companies that took part in the research have their account on this site.

However, despite of the lack of popularity against other SNSs, it should be noted that the structure of the firms present on Tweeter seems to be consistent with the general structure of the sample in relation to the company value. Enterprises of medium value, i.e. between PLN 1000 and 5000 million are the most interactive ones. This particular group of companies has the highest number of such indicators as tweets per company or the number of followers per company.

Finally, it must be stressed that there is one deviation from the trend identified and described above that relates to the abundance of EB activities in the group of medium-sized enterprises. Exceptionally, the index of likes per one tweet is the lowest and 0.06 . The ratio of 0.13 is to be seen for companies with a lower value, and the ratio of 0.16 is to be found for the companies with the value of over PLN 5000 million. 
Table 3. Facebook, LinkedIn, YouTube and Twitter statistics in all the companies and in relation to their size

\begin{tabular}{|c|c|c|c|c|c|c|c|c|c|}
\hline \multicolumn{10}{|c|}{ Facebook } \\
\hline \multicolumn{2}{|c|}{ Statistics } & 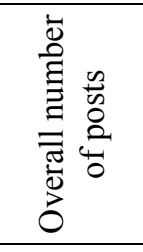 & 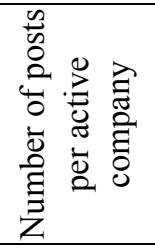 & 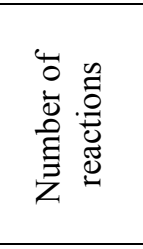 & 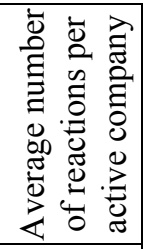 & 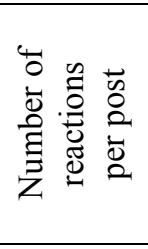 & 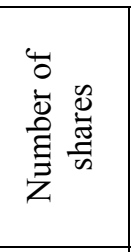 & 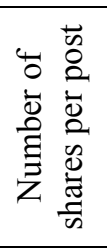 & 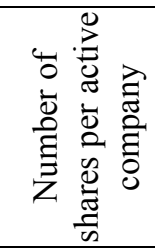 \\
\hline \multirow{3}{*}{$\begin{array}{l}\text { Com- } \\
\text { pany } \\
\text { value } \\
\text { (in mil- } \\
\text { ions } \\
\text { PLN) }\end{array}$} & $\begin{array}{l}\text { up to } \\
1000\end{array}$ & 366 & 14,64 & 49641 & 1985,64 & 135,63 & 2898 & 7,92 & 115,92 \\
\hline & $\begin{array}{l}1000- \\
5000\end{array}$ & 520 & 18,57 & 127711 & 4561,11 & 245,60 & 5416 & 10,42 & 193,43 \\
\hline & $\begin{array}{l}\text { above } \\
5000\end{array}$ & 176 & 17,6 & 26773 & 2677,3 & 152,12 & 1306 & 7,42 & 130,60 \\
\hline \multicolumn{2}{|l|}{ Total } & 1062 & 16,85 & 204125 & 3240,08 & 192,21 & 9620 & 9,06 & 152,70 \\
\hline \multicolumn{10}{|c|}{ LinkedIn } \\
\hline \multicolumn{2}{|c|}{ Statistics } & 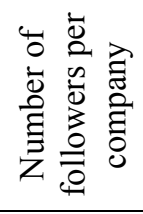 & 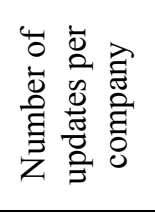 & $\begin{array}{l}4 \\
0 \\
\dot{0} \\
0 \\
0 \\
0 \\
\vdots \\
z\end{array}$ & 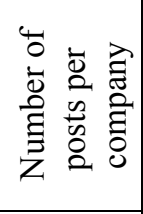 & 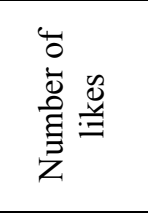 & 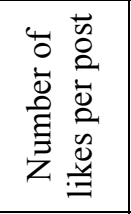 & 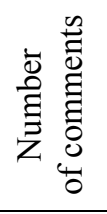 & 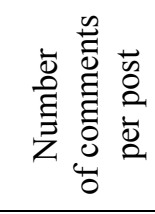 \\
\hline \multirow{3}{*}{$\begin{array}{l}\text { Com- } \\
\text { pany } \\
\text { value } \\
\text { (in mil- } \\
\text { ions } \\
\text { PLN) }\end{array}$} & $\begin{array}{l}\text { up to } \\
1000\end{array}$ & 1166 & 21,89 & 57 & 2,85 & 1298 & 22,77 & 33 & 0,58 \\
\hline & $\begin{array}{l}1000- \\
5000\end{array}$ & 2346 & 40,81 & 81 & 3 & 1300 & 16,05 & 62 & 0,77 \\
\hline & $\begin{array}{l}\text { above } \\
5000\end{array}$ & 3757 & 68,18 & 40 & 5 & 871 & 21,78 & 35 & 0,88 \\
\hline \multicolumn{2}{|l|}{ Total } & 2027 & 36,27 & 178 & 3,24 & 3469 & 19,49 & 130 & 0,73 \\
\hline \multicolumn{10}{|c|}{ YouTube } \\
\hline \multicolumn{2}{|c|}{ Statistics } & 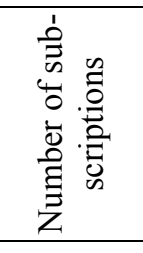 & 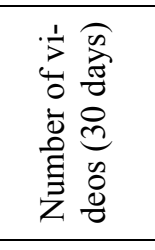 & 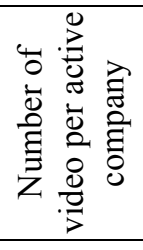 & 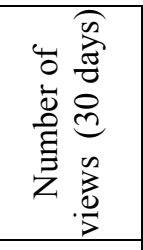 & 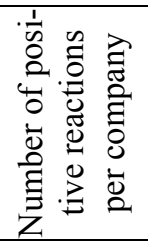 & 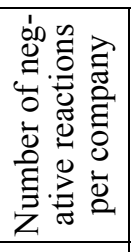 & 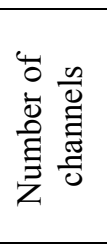 & 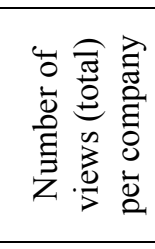 \\
\hline \multirow{3}{*}{$\begin{array}{l}\text { Com- } \\
\text { pany } \\
\text { value } \\
\text { (in mil- } \\
\text { ions } \\
\text { PLN) }\end{array}$} & $\begin{array}{l}\text { up to } \\
1000\end{array}$ & 28231 & 27 & 2,70 & 189724 & 101,80 & 49,70 & 2,90 & 1022355 \\
\hline & $\begin{array}{l}1000- \\
5000\end{array}$ & 207598 & 177 & 11,80 & 257028 & 480,93 & 138,60 & 4,40 & 9603542 \\
\hline & $\begin{array}{l}\text { above } \\
5000\end{array}$ & 102601 & 9 & 1,29 & 26513 & 4,29 & 1,29 & 1,43 & 890025 \\
\hline \multicolumn{2}{|l|}{ Total } & 338430 & 213 & 6,66 & 185571 & 258,19 & 80,78 & 3,28 & 5364249 \\
\hline \multicolumn{10}{|c|}{ Twitter } \\
\hline \multicolumn{2}{|c|}{ Statistics } & 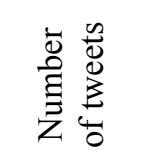 & 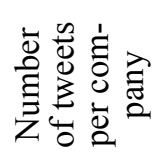 & 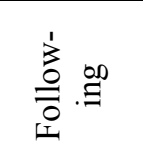 & 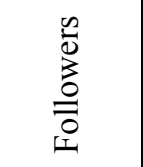 & 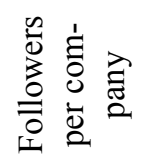 & $\begin{array}{l}\mathscr{d} \\
: \frac{1}{3}\end{array}$ & $\frac{n}{n}$ & 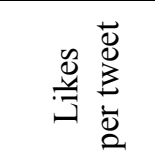 \\
\hline \multirow{3}{*}{$\begin{array}{l}\text { Com- } \\
\text { pany } \\
\text { value } \\
\text { (in mil- } \\
\text { ions } \\
\text { PLN) }\end{array}$} & $\begin{array}{l}\text { up to } \\
1000\end{array}$ & 5833 & 145,82 & 282 & 4148 & 103,7 & 750 & 0 & 0,13 \\
\hline & $\begin{array}{l}1000- \\
5000\end{array}$ & 98961 & 2019,6 & 2891 & 106091 & 2165,12 & 6370 & 6 & 0,06 \\
\hline & $\begin{array}{l}\text { above } \\
5000\end{array}$ & 5492 & 499,3 & 371 & 10316 & 937,81 & 889 & 1 & 0,16 \\
\hline \multicolumn{2}{|l|}{ Total } & 110286 & 1102,86 & 3544 & 120555 & 1205,55 & 8009 & 7 & 0,07 \\
\hline
\end{tabular}




\section{Conclusions}

In the modern world in which information serves as a primary source of company value, it is necessary for business enterprises to undertake various activities related to information management. The problem of obtaining and providing information in the right place and time seems to be of particular importance in this context. Effective efforts in this area carried out through the use of social media sites can play a key role in ensuring the success of the company. Employer branding created through the company's presence on various websites is currently one of the most important strategies for building positive relationships with stakeholders and human resource management.

Research results allow us to believe that despite the social media presence of many top-rated companies, their activities in this area are often accidental, inconsistent, and even inappropriate but also stem from a current fashion rather than be the result of a consistent implementation of the company's strategy. Only half of the companies surveyed in the research are present on three or four sites, whereas a total of $20 \%$ have only one account or prefer to keep away from the Internet in general. In addition, the fact that the presence on a given site does not translate to the intensity of current activity within the message recipients is a particularly important strategic mistake in the implementation of employer branding.

The detailed research results also indicate that companies that have a value in the range between 1000 and 5000 million PLN are more often present in the Internet than other companies. Medium-sized companies are also more active in almost all of the areas within the period.

The results show that most of the companies analysed have not adopted a systematic approach to the external employer branding practices they use. Therefore a conclusion might be drawn that, although these enterprises are present in the social media networks, and they use various external communication channels in order to reach their stakeholders, they still fail to adopt a strategic orientation in developing their activities.

The conclusions are a part of a preliminary research and will offer more input when followed by an in-depth content analysis. Moreover, they can be treated as a benchmark for a comparative analysis of the social media usage in other countries.

\section{Limitations}

In addition to the considerations above, certain limitations to the obtained results should be pointed out. First of all, only 100 of the most valuable private companies were analyzed. It is possible that these dependencies would not appear in state-owned companies or non-profit organizations, as well as companies of a much lower value. This is certainly an area for future research. The second important aspect that may be relevant to these conclusions is related to the selection of only the four most popular sites for the research. Further research should therefore be extended to other SNS. Thirdly, it should be stated that the period of the companies' activity selected for the analysis was the period of 30 days from January 15th and February 15th 2018. At that time Fat Thursday (February 8) and Valentine's Day (February 14) were celebrated. These two events could have influenced any additional activity of Internet users, and thus make it difficult to assess the activity of the surveyed companies.

Taking into account these limitations, it is worth continuing and expanding research in this area. The results may be of significant importance to many enterprises in the scope of their external employer branding strategy in social media.

\section{References}

Aboul-Ela, G. M. B. E. (2016). Employer branding: What constitutes "An Employer of choice? Journal of Business and Retail Management Research (JBRMR), 11(1), 154-166.

Aguenza, B. B., \& Som, A. P. M. (2012). A conceptual analysis of social networking and its impact on employee productivity. IOSR Journal of Business and Management, 1(2), 48-52. https://doi.org/10.9790/487X-0124852

Alnıaçık, E., \& Alnıaçık, Ü. (2012). Identifying dimensions of attractiveness in employer branding: Effects of age, gender, and current employment status. Procedia - Social and Behavioral Sciences, 58(2012, October), 1336-1343.

https://doi.org/10.1016/j.sbspro.2012.09.1117

Ambler, T., \& Barrow, S. (1996). The employer brand. The Journal of Brand Management, 4(3), 185-206. https://doi.org/10.1057/bm.1996.42

Anon. (2016). SHRM survey Findongs: Using social media for talent acquisition - recruitment and screening. Retrieved from https://www.shrm.org/hr-today/trendsand-forecasting/research-and-surveys/Documents/ SHRM-Social-Media-Recruiting-Screening-2015.pdf

Anon. (2017). Information society in Poland. Results of statistical surveys in the years 2013-2017.

Bellou, V., Chaniotakis, J., Kehagias, J., \& Rigopoulou, I. (2015). Employer brand of choice: an employee perspective. Journal of Business Economics and Management, 16(6), 1201-1215.

https://doi.org/10.3846/16111699.2013.848227 
Chiang, J. K. H., \& Suen, H. Y. (2015). Self-presentation and hiring recommendations in online communities: Lessons from LinkedIn. Computers in Human Behavior, 48, 516-524.

https://doi.org/10.1016/j.chb.2015.02.017

Chunpinga, Y., \& Xib, L. (2011). The study on employer brand strategy in private enterprises from the perspective of human resource management. Energy Procedia, 5, 2087-2091.

https://doi.org/10.1016/j.egypro.2011.03.360

Dögl, C., \& Holtbrügge, D. (2014). Corporate environmental responsibility, employer reputation and employee commitment: An empirical study in developed and emerging economies. International Journal of Human Resource Management, 25(12), 1739-1762. https://doi.org/10.1080/09585192.2013.859164

Edwards, M. R. (2010). An integrative review of employer branding and OB theory. Personnel Review, 39(1), 523. https://doi.org/10.1108/00483481011012809

Forbes. (2017). Największe polskie firmy prywatne 2017. Ranking "Forbesa". Retrieved from https://www. forbes.pl/rankingi/100-najwiekszych-firm-prywatnych-w-polsce-2017/twwjf75

Gibbons, J. (2006). Employee engagement: A review of current research and its implications. New York, NY: The Conference Board, Inc., 1-23.

Granovetter, M. (1985). Economic action and social structure: The problem of embeddedness. American Journal of Sociology, 91(3), 481-510. https://doi.org/10.1086/228311

HRM Institute. (2017). Raport employer branding $w$ Polsce 2017. Human Resource Management Institute. Retrieved from https://www.employerbrandingsummit. pl/raport-eb-2017/

Hughes, D. J., Moss, R., Batey, M., \& Lee, A. (2012). A tale of two sites: Twitter vs. Facebook and the personality predictors of social media usage. Computers in Human Behavior, 28(2), 561-569. https://doi.org/10.1016/j.chb.2011.11.001

Kaplan, A. M., \& Haenlein, M. (2010). Users of the world, unite! The challenges and opportunities of Social Media. Business Horizons, 53(1), 59-68. https://doi.org/10.1016/j.bushor.2009.09.003

Kaplan, A. M., \& Haenlein, M. (2011). The early bird catches the news: Nine things you should know about microblogging. Business Horizons, 54(2), 105-113. https://doi.org/10.1016/j.bushor.2010.09.004

Kietzmann, J. H., Hermkens, K., McCarthy, I. P., \& Silvestre, B. S. (2011). Social media? Get serious! Understanding the functional building blocks of social media. Business Horizons, 54(3), 241-251. https://doi.org/10.1016/j.bushor.2011.01.005

Kissel, P., \& Büttgen, M. (2015). Using social media to communicate employer brand identity: The impact on corporate image and employer attractiveness. Journal of Brand Management, 22(9), 755-777. Retrieved from http://link.springer.com/10.1057/bm.2015.42

Kucherov, D., \& Zavyalova, E. (2012). HRD practices and talent management in the companies with the employer brand. European Journal of Training and Development, 36(1), 86-104.

https://doi.org/10.1108/03090591211192647

Lloyd, S. (2008). Branding from the inside out. Business Strategy Review, 19(2), 64-66.

Miles, S. J., \& Mangold, G. (2004). A conceptualization of the employee branding process. Journal of Relationship Marketing, 3(2/3), 65-87. https://doi.org/10.1300/J366v03n02 05

Priyadarshini, C., Kumar, Y. L. N., \& Jha, R. R. (2017). Employer attractiveness through social media: A phenomenological study. The Qualitative Report, 22(4), 969983. Retrieved from

http://nsuworks.nova.edu/tqr\%0A

http://nsuworks.nova.edu/tqr/vol22/iss $4 / 3$

Rampl, L. V. (2014). How to become an employer of choice: transforming employer brand associations into employer first-choice brands. Journal of Marketing Management, 30(13-14), 1486-1504. https://doi.org/10.1080/0267257X.2014.934903

Reis, G. G., \& Braga, B. M. (2016). Employer attractiveness from a generation perspective: Implications for employer branding. Revista de Administração, 51(1), 103116. https://doi.org/10.5700/rausp1226

Rosaci, D., \& Sarne, G. M. L. (2014). Matching users with groups in social networks. In F. Zavoral, J. J. Jung, C. Badica (Eds.). Intelligent distributed computing VII (pp. 45-54). Springer. https://doi.org/10.1007/978-3-319-01571-2_7

Sengupta, A., Bamel, U., \& Singh, P. (2015). Value proposition framework: implications for employer branding. Decision, 42(3), 307-323. https://doi.org/10.1007/s40622-015-0097-x

Smith, A. N., Fischer, E., \& Yongjian, C. (2012). How does brand-related user-generated content differ across YouTube, Facebook, and Twitter?. Journal of Interactive Marketing, 26(2), 102-113.

https://doi.org/10.1016/j.intmar.2012.01.002

Smith, W. P., \& Kidder, D. L. (2010). You've been tagged! (Then again, maybe not): Employers and Facebook. Business Horizons, 53(5), 491-499. https://doi.org/10.1016/j.bushor.2010.04.004

Stieglitz, S., \& Dang-Xuan, L. (2013). Emotions and information diffusion in social media - Sentiment of microblogs and sharing behavior. Journal of Management Information Systems, 29(4), 217-248. https://doi.org/10.2753/MIS0742-1222290408.

Tavleen, K. (2013). Role of social media in building image of an organization as a great place to work. Proceedings of $A S B B S, 20(1), 546-553$.

Theurer, C. P., Tumasjan, A., Welpe, I. M., \& Lievens, F. (2018). Employer branding: A brand equity-based literature review and research agenda. International Journal of Management Reviews, 20(1), 155-179. https://doi.org/10.1111/ijmr.12121

Utz, S. (2015). The function of self-disclosure on social network sites: Not only intimate, but also positive and entertaining self-disclosures increase the feeling of connection. Computers in Human Behavior, 45(2015, April), 1-10. https://doi.org/10.1016/j.chb.2014.11.076 